\title{
The Sociogram: The Analysis Of Interpersonal Relationships In Higher Education
}

Isabel-María Ferrándiz-Vindel, Ph.D., University of Castilla-La Mancha, Spain Berta Castejón Jiménez, University of Castilla-La Mancha, Spain

\begin{abstract}
The environmental and professional conditions are doing at university's education an 'imposition' of a teaching-learning process and its assessment. Nowadays, a new function is demanded to the university's teacher, not just as a facilitator of his/her students' learning but also as a group dynamiter, team-works. At High Education, more and more frequently, it begins to get power to the necessity for answering to training apart from providing concepts to its professionals, to contribute with the instrumental and attitudinal resources which qualify them professionally to develop the tasks. According to the new use of didactic and organisational proposals at the High Education, High is essential that departs from concepts such as 'work through projects', 'interpersonal relationships', 'creativity'... it is placed in points of view of the university teachers' quality development. The hole structural change we have fulfilled with the European's Space of High Education (EEES) will not mean nothing if people continue doing the same as they used to do before in terms of pedagogic language.

What would we like to share in this communication? The main aim of this communication is to present the sociogram as other resource to use at High Education, to analyse competence among university groups, to make team-works distinguishing between relationships established by friendship and by other interests the students have. Furthermore, the pedagogical implications for the teacher not only by the results that they have obtained but also because of the structure and grade of cohesion in the class-group, its dynamic and function as a university group in order to orientate and give us the possibility to act in an individual way with each of the students.
\end{abstract}

Keywords: High Education; Sociogram; Team-Works; Pedagogical Implications

\section{INTRODUCTION}

ince Spain takes part in the European Union it has been implied in an amount of changes. In the university frame, we highlight the implantation of the Bolonia's Plan which has been the popular nomination through which we know the adaptation of university to a common system for all of Europe (Fernández Hernández, 2000).

One of these changes which support this process of the modification is at the consciousness of the importance which gives attention at the process of learning-teaching. To obtain that teachers and students participate in a more involving way during this process, it will make possible that they know, interpret and make their own curricular proposals in the integral professional competences frame.

Our educative system is immerse in a change process because people which compound it, they change by believing in a inclusive and integrative University what is going to make an important transformation of methodologies, assessment, contents and so on and furthermore a change of mentality of the whole university community. What it is more, this system must attend to the necessities that come from each of us as individual part. 
They have to take on mind the individual characteristics of each of the persons that are involved in the processes of learning-teaching of all the levels of our university system (Simon y Albert, 1989: 316).

Focusing on the High Education, the latest years we have suffer a wide amount of changes that have given us the obliged advance in the university reality. In that way professors, students and so on have decided to realized an exhaustive and precise effort to get into that new way of understanding the education at university; the European Convergence.

The European Frame of High Education promotes that the students acquire a central and main paper, they are consider as an active and participative member.

The participation, know as civic competence, must be a formative content learnt by the students on their pass through the university with the main aim of converse in active citizens, commitment and responsible with the society (Michavila, 2008, 1).

We do not look for a student closed on himself/herself and on his/her knowledge but we are trying to establish dialogues and discussions with a huge range of theoretical support but in the way that people know what they ideas are.

The new relation that exist between the students of EEES looks for a true collaborative learning which achieve to get aims high rates both in the 'tutorial relation' which formulates a group-learning and also the search of collaboration among the expert students and the rookie student with the advantage of socio-cognitive proximity that exists among the elements which are related and the 'collaborative learning' where each member of the group has the same level of responsibility creating structures that look for the identity at tasks and also to rewards. This kind of learning is more feasible if the ability is heterogeneous and the competence of their members. (Serrano, 1996)

Therefore, in the new European Space pretends to promote among the students new ways of relation which pretends to obtain sharing among them information, knowing that it is supposed to train to the group for understanding without trying to be a treat.

The key documents where the necessities are picked we can observe the students participation in the Quality of Guarantee, which are the conferences of ministries responsables of High Education at the Bolonia's Process:

- $\quad$ Statement of Berlín '03: “They agree that by 2005 national quality assurance systems should include (...) participation of students (...)."

- $\quad$ Statement of Bergen '05: 'However, we have to progress more over, particularly what it refers to the participation of the students and the International participation'. 'We adopt the standards and guidelines for the Quality of Guarantee in the EEES proposed by ENQA'.

- $\quad$ Statement of London '07: 'Garantee of Quality (...). The participation of the students has increased since 2005 to all the levels although it is necessary to improve on it' (Galán Palomares, Fernando Miguel, 2008, 2)

\section{METHODOLOGY}

The reason that takes us to realise the study about the interpersonal relationships at an university frame, obeys to some reasons, among them we are going to highlight:

- $\quad$ There are just some experiences done about the analysis of the interpersonal relationships at the university students.

- $\quad$ The use of the sociogram can help us to know and understand better the social relations in a group of students.

- It offers the chance to identify the groups that exist in a university class. 
The objective of this study is to analyse the interpersonal relationships of students of Psicopedagogía in the Special Education subject by using the sociogram with some items that reflect competence for understanding to whom and for whom create different teams of work, in concrete:

- $\quad$ To select to whom make an investigation project

- $\quad$ To select to whom make a creative work

- $\quad$ To select to whom organise a playful-creative event

The design used was a case-design; when the class-group has been together for four months of 'coexistence'. The case-design is an investigation process by which is mainly focused in understanding a specific event which takes part in a daily context that includes a wide variety of information.

The sample of referente by a Group of 66 students of the Psicopedagogía Degree all of those who were registered in the Especial Education' subject at the University of Castilla-La Mancha, more in concrete at the campus of Cuenca. 50 of them were women (a $75.7 \%$ of the sample) and 16 men (which corresponds to a $24.3 \%$ of the sample). From the whole obtained of the sample, the $100 \%$ are degree in the different specialities of Magisterio, which is been 26 years old the medium age of the sample.

\section{RESULTS}

After Licking the answers given, we start by analysing with the elaboration of a table of frequencies to each of the questions done.

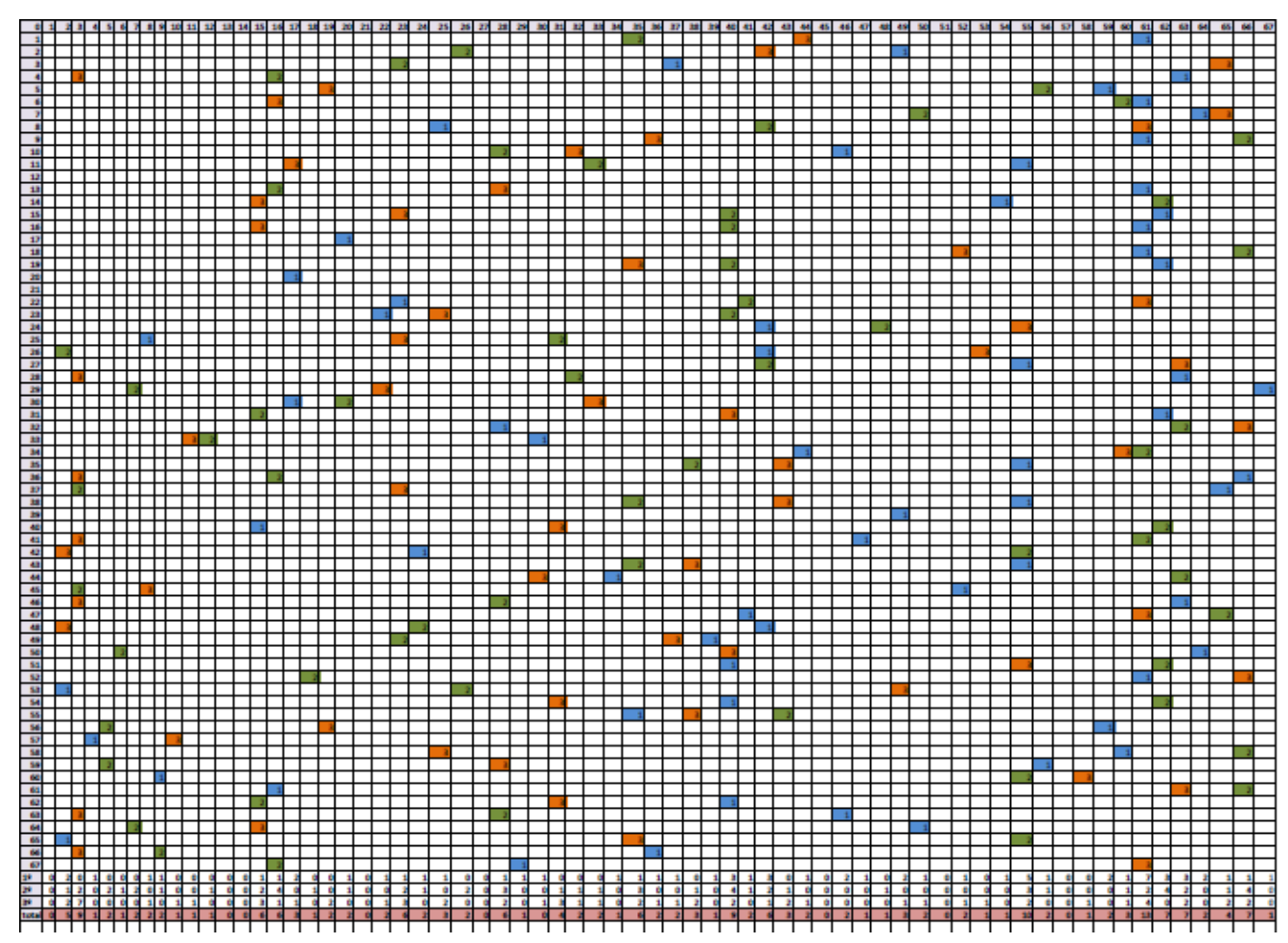

With the results obtained, we start by analyse each of the questions to know how students are considered by their classmates with a good coordinator or leader. 
We focus our attention as the first step to the election to 'better coordinator to realise an investigation process' and it is the student number 61. It is the student who has obtained high punctuation from his/her classmates as a total, that is to say that we have counted the votes from the first, second and third option. In total, there are 19 people that consider the student 61 as the best or one of the best from the class to work in a group by doing a work through projects.

More over than the student who has obtained more votes in total, the student 61 at the same time has been the one that his/her classmates of Psicopedagogía to the ones we pass the questionnaires consider more qualified to realise work through projects. That is to say, they elected him/her as a high number of elections as a first option $(\mathrm{n}=7)$.

It is very interesting to show the sub-group that has been formed in the sociogram through the votes done to the student number 61 . We want to highlight that this student is not the delegate of the class, the students recognise which competences must have a good coordinator of a good project what are different to the ones that a delegate has as a 'coordinator of a big group'.

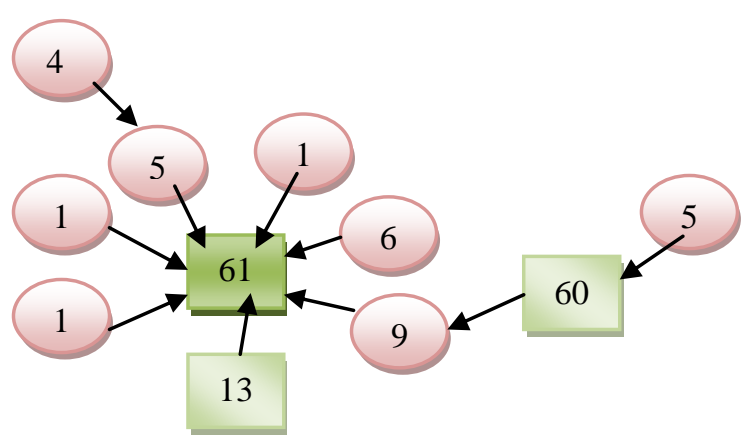

In the second place, with the election of 'the best coordinator to realise a creative work', the first election done by the group, it gives as a result that the students 34 and 64 are the most voted in the first place with a total of 4 votes.

If we analyse these votes, we should look to the first place that in the student 34 is one of the 17 boys of the class of the Group-class of Psicopedagogía. It is, again, a bit surprising because it is once more the mot elected by the most part of the elections of the classmates of Psicopedagogía. This is a fact we may consider because the genre real percentage of the class that we have found in the class. It is logical to think that by statistics and probabilities, this student should be a girl because it is a bigger number of girls who participated than boys at the class of Psicopedagogía.

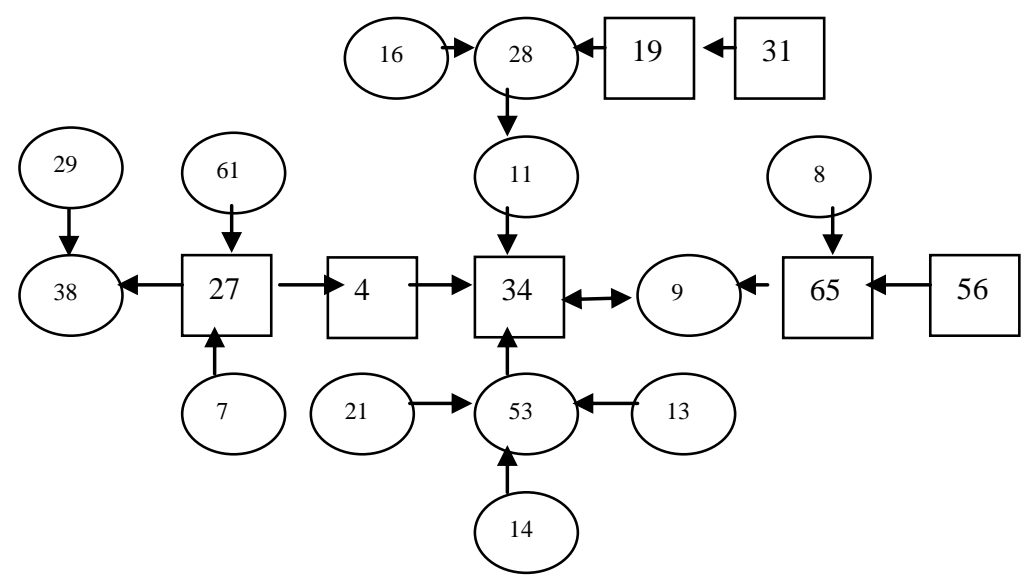


The leader of the 'third question': organise a playful-creative event, that is to say the one who has obtained more elections $(9.09 \%)$ in the first place has been the student 62 who is a girl that has obtained six elections and it has probably been because of empathy that manifestates and also the efficient and creative way of working. The election of the leader is due to the person with big creative gifts and also in leadership, able to move the group in a clear way without any problems treating at each moment to control de situation with the main aim of doing the job in an efficient manner.

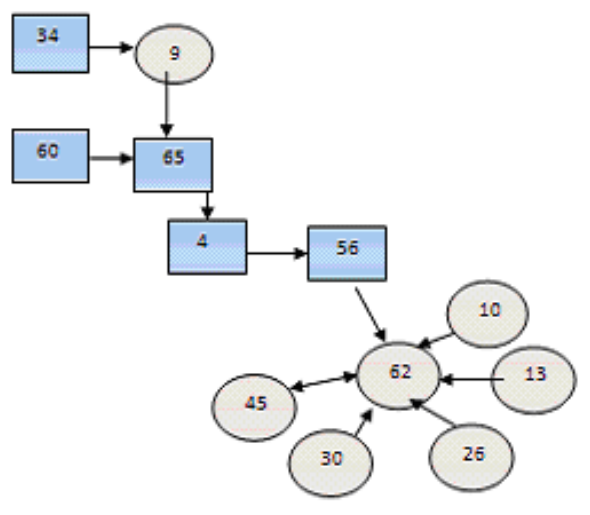

\section{CONCLUSIONS}

Following Rodríguez Pérez. A y Morera. B. (2001) the sociogram is a technique which determines the preferences of individuals respect to diverse stimulus from those person who take part in their medium. In fact, it is used a molecular analogy for representing the relation between the members of a group apart from the answers to some questions about their preferences in the context of the group. A sociometric punctuation constitutes, in essence, the Lumber of times that a subject has been elected by other individuals for carrying certain objectives. It is more over a representation of the conscious prevalence.

By this work, we have wanted to prove that this tendency to select and prefer must be conscious to serve, moreover, to the necessity of having a perception of the organised and useful world for validating our conception of the reality. For that, we have to know:

- $\quad$ The relations that exist among the individuals and also the intensity of them.

- The grade of cohesion of the group. The informal structure of the group and the existence of the subgroups. The position of each member in position to the others.

- $\quad$ The grade of socialization of individuals of the group.

Following Vázquez-Reina, M. (2009) this technique has provide us a very useful information about the dynamic and functionality of the class for guiding and acting by an individual manner with each of our students. Those are some of the pedagogical uses:

- Describe the internal structure of the group, its organization, cohesion and who are the members more significant on it. To observe the couple, triangle or sub-groups relations among the students.

- $\quad$ To guide about values and qualities more appreciate or challenges in the class depending on those who form part of the members more acceptable or rejected.

- To permit actuation with the students more isolated or rejected by the group. You can seek more attention, assign them representative tasks which are valued by the rest or integrate them in work-groups more adaptable to their personalities. 
After doing this study, we have proved that some of the university students of $1^{\text {st }}$ Psicopedagogía have acquired the capacity of competence to discern to whom and what for form different teams of work depending on the task or activity making distinction between the relations created on one hand by friendship and, on the other hand, by the interests which have been created in function of the activity proposed.

\section{AUTHOR INFORMATION}

Isabel $\mathrm{M}^{\mathrm{a}}$ Ferrándiz Vindel, $\mathrm{PhD}$ and Degree in Education Sciences by Complutense University of Madrid (UCM), Spain. Professor in Pedagogy Department. Faculty of Education Sciences and Humanities of Cuenca. University of Castilla-La Mancha (Spain). E-mail: Isabel.Ferrandiz@uclm.es

Research Interest: inclusive education of disabled people and (or reduced mobility in all educational levels and the training of those professional who will teach them.

Berta Castejón Jiménez, Degree in Education Sciences by University of Castilla-La Mancha (UCLM), Spain. Professor in Primary School. E-mail: bertacastejon77@hotmail.com

Research Interest: inclusive education of disabled people and/or reduced mobility in all educational levels

\section{REFERENCES}

1. Artavia, J. M. (2005): Interacciones personales entre docentes y estudiantes en el proceso de enseñanza y aprendizaje. Revista Electrónica “Actualidades investigativas en Educación”, Julio-Diciembre, 1-19

2. Ramírez, J. (2009): El sociograma: una herramienta para analizar las relaciones en el aula. Recuperado el 16 de Junio del 2010, de: http://trabajosocialsalud.blogspot.com/2009/08/el-sociograma-una-herramientapara.html

3. Rodríguez, A. and Morera, D. (2001): El sociograma: estudio de las relaciones informales en las organizaciones. Madrid: Pirámide, D.L.

4. Serrano, J. M. (1996): El aprendizaje cooperativo. En J.L. Beltrán y C. Genovard (Edit.) Psicología de la Instrucción I. Variables y procesos básicos. Madrid: Editorial Síntesis, S.A. Cap.5, págs. 217-244.

5. Fernández, M. (2000): Las relaciones interpersonales en la infancia: sus problemas y soluciones. Málaga: Aljibe.

6. Simon, P. and Albert, L. (1989): Las relaciones interpersonales: ejercicios prácticos y fundamentos teóricos. Barcelona: Herder.

7. Vázquez, M. (2009): El sociograma: una herramienta para analizar las relaciones en el aula. Recuperado el 16 de Junio del 2010, de: http://trabajosocialsalud.blogspot.com/2009/08/el-sociograma-una-herramientapara.html 